\title{
Roles of Reactive Oxygen Species in the Fate of Stem Cells
}

\author{
Pooja Chaudhari, Zhaohui Ye, and Yoon-Young Jang
}

\begin{abstract}
Significance: Stem cells are characterized by the properties of self-renewal and the ability to differentiate into multiple cell types, and thus maintain tissue homeostasis. Reactive oxygen species (ROS) are a natural byproduct of aerobic metabolism and have roles in cell signaling. Regulation of ROS has a vital role in maintaining "stemness" and differentiation of the stem cells, as well as in progression of stem-cell-associated diseases. Recent Advances: As of late, much research has been done on the adverse effects of ROS in stem cells. However, recently it has become apparent that in some cases redox status of the stem cell does have a role in maintaining its identity as such. Both pluripotent and multipotent stem cell types have been reported to possess enzymatic and nonenzymatic mechanisms for detoxification of ROS and to correct oxidative damage to the genome as well as the proteome. Critical Issues: Although context dependent and somewhat varied among different stem cell types, the correlation seems to exist between antioxidant defense level and stem cell fate change (i.e., proliferation, differentiation, and death). Changes in stem cell redox regulation may affect the pathogenesis of various human diseases. Future Directions: Dissecting the defined roles of ROS in distinct stem cell types will greatly enhance their basic and translational applications. Here, we discuss the various roles of ROS in adult, embryonic, and induced pluripotent stem cells. Antioxid. Redox Signal. 20, 1881-1890.
\end{abstract}

\section{Introduction}

$\mathbf{O}$ XYGEN SPECIES that are more reactive than free oxygen are collectively called reactive oxygen species (ROS). ROS comprise of superoxide, hydrogen peroxide $\left(\mathrm{H}_{2} \mathrm{O}_{2}\right)$, the hydroxyl radical, singlet oxygen, and nitric oxide. Excessive amounts of ROS can bring about cellular senescence, apoptosis, or carcinogenesis (5). ROS-induced cellular damage may also contribute to stem cell aging (63). Under physiological conditions, mitochondria are the main source of ROS (5). Mitochondria continuously produce low levels of superoxide anion as a byproduct of oxidative phosphorylation, which is then rapidly converted into $\mathrm{H}_{2} \mathrm{O}_{2}$ by mitochondrial superoxide dismutase (SOD) (66). $\mathrm{H}_{2} \mathrm{O}_{2}$ can be converted into highly toxic hydroxyl radicals or may be eliminated by the action of glutathione peroxidase, peroxiredoxin, or catalase $(18,31,55)$. NADPH oxidase complexes in cells also have an active ROS-generating system. ROS act as cell signaling molecules with a homeostatic function at low levels or may prove to be detrimental at high levels by increasing tissue injury. Consequently, elevated ROS have been implicated in cellular transformation and progression of multiple diseases, including tumor. Recent findings have shed much light on the role of ROS in different types of stem cells in both stem cell maintenance and in their differentiation.

Stem cells are undifferentiated cells possessing the ability to renew themselves indefinitely or differentiate to give rise to a specialized cell type, which may be either fully differentiated or may still possess the ability to give rise to other specialized cell types. These cells are thus of much importance in the regenerative medicine. Adult stem cells (ASCs), such as hematopoietic stem cells (HSCs), have long been used for transplantation purposes (46). Pluripotent stem cells, such as embryonic stem cells (ESCs) and induced pluripotent stem cells (iPSCs), have recently brought forth a new avenue for cell therapy. Especially, iPSCs have enormous potential for the development of patient-specific cell and drug therapy $(13,14$, $16,49)$.

iPSCs are generated by reprogramming the genome of somatic cells to a pluripotent state, similar to that seen in the ESCs, by the introduction and forced expression of pluripotency-related transcription factors and genes. The generation of iPSCs was first reported by Takahashi and Yamanaka in 2006, by retroviral transduction of the Oct4, Sox2, Klf4, and 
c-Myc genes in mouse somatic fibroblasts (81). Subsequently, human iPSCs were generated from various somatic cell types $(1,14,40,49,50,52,95)$. Over the past 5 years, significant advances have been made in the iPSC generation and differentiation technology $(14,26,47,49,60,95,96)$. Since both reprogramming and lineage specification of stem cells involve dramatic cellular fate transformation that is ultimately important for therapy, it is of interest to study the role of ROS in the self-renewal and differentiation of the different stem cell types.

\section{Role of ROS in Pluripotent Stem Cells}

A vast majority of cellular ROS arises from superoxide anions generated in the mitochondria. Human ESCs seem to maintain their genomic identity by enhanced ROS removal capacity as well as limited ROS production, due to the small number of mitochondria present in the ESCs (3). A recent study reveals that human iPSC generation process is able to effectively reduce the mitochondrial genome copy number present in the parental fibroblasts, and moreover human iPSCs have similar ROS levels and antioxidant defenses to those seen in ESCs, showing downregulation of GSR (glutathione reductase), SOD2 (Mn-dependent superoxide dismutase), three transcript variants of MGST1 (microsomal glutathione S-transferase 1), and MAPK26 (mitogen-activated kinase 26) in a fashion similar to human ESCs (3). Additionally, one of the iPSC clones also showed downregulation of GSTA3 (glutathione S-transferase), GPX2 (glutathione peroxidase 2), and HSPA1B (heat shock protein 1B) and upregulation of HSPB1 (heat shock protein 1) in a manner similar to human ESCs. Based upon a mouse iPSC and hepatic differentiation study, high expression of antioxidant genes was detected in both iPSCs and hepatic cells differentiated from iPSCs compared with mouse embryonic fibroblasts (MEFs) (47).

It has been suggested that murine ESCs have a superior stress defense as compared with that of various differentiated murine cells (70). Multiple pathways may contribute to this, including the verapamil-sensitive multidrug efflux pump, antioxidant defense, DNA strand break repair, and heat shock protein expression. The glutathione/thioredoxin system forms an important defense against ROS accumulation (73), and the enzyme complex Tgr (thioredoxin-glutathione reductase), which is responsible for the regeneration of glutathione (80), is downregulated upon differentiation. A similar activity decrease is seen for SOD2, which is regarded to be the primary defense of the cell against ROS (42). This study also identified four heat shock proteins that undergo downregulation upon differentiation of murine ESCs. Namely, Hspb1, which regulates SOD2 expression levels (79, 97); Hspa1b, which is known to confer resistance against apoptosis to cells (29); Hspa1a, which makes the expression other heat shock proteins inducible in events of cellular stress (7); and Hspa9a, which has been implicated in stress response $(11,38)$, control of cell proliferation (39), and cell differentiation (91).

The superior antioxidant defense capability present in normal (i.e., healthy donor derived) iPSCs seems to decrease in disease-relevant conditions as evidenced by a recent study on human iPSCs derived from Parkinson's disease patients that carry the p.G2019S mutation in the Leucine Rich Repeat Kinase-2 (LRRK2) gene (Fig. 1); the dopaminergic (DA) neurons derived from these mutant iPSC lines show increased susceptibility to oxidative stress and CASP3 activation on treatment with $\mathrm{H}_{2} \mathrm{O}_{2}$ during all stages of neuronal differentiation (60). These G2019S-iPSC-derived DA neurons also showed higher susceptibility to 6-hydroxydopamine, which can lead to destruction of DA neurons by formation of free radicals and/or inhibition of the mitochondrial complexes I and $\operatorname{IV}(6,21,60,71)$.

Another study also supports the aforementioned hypothesis by revealing the effects of a single minimally toxic episode of $\operatorname{ROS}\left(\mathrm{H}_{2} \mathrm{O}_{2}\right)$ on mouse ESCs (58). The initial response to such an episode in mouse ESCs is to maintain a rapid growth rate and bypass DNA repair. The study demonstrates that a single minimally toxic exposure to ROS is sufficient to induce

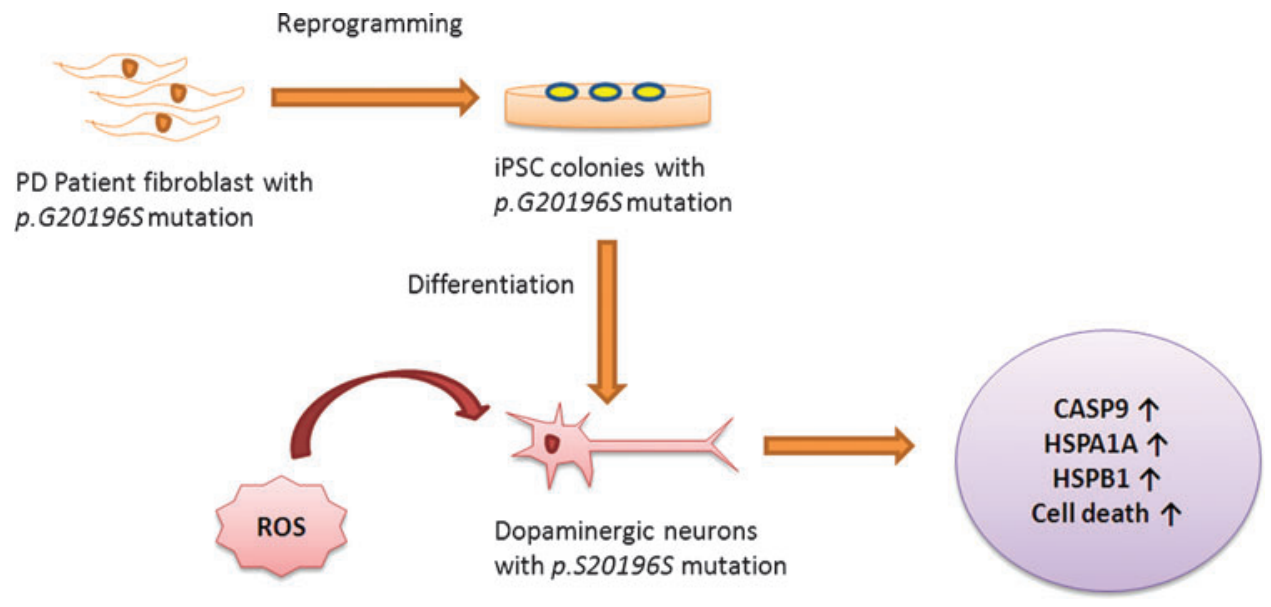

FIG. 1. Increased susceptibility of LRRK2 mutant iPSC-derived DA neurons to ROS. On exposure to stress agents, such as hydrogen peroxide, MG-132, and 6-hydroxydopamine, Parkinson's disease (PD) G2019S-iPSC-derived DA neurons showed increased expression of oxidative stress response genes CASP9, HSPA1A, and HSPB1 and increased cell death as compared with unaffected neurons. LRRK2, Leucine Rich Repeat Kinase-2; iPSC, induced pluripotent stem cell; DA, dopaminergic; ROS, reactive oxygen species; HSPA1A, heat shock protein 1A; HSPB1, heat shock protein 1 . To see this illustration in color, the reader is referred to the web version of this article at www.liebertpub.com/ars 

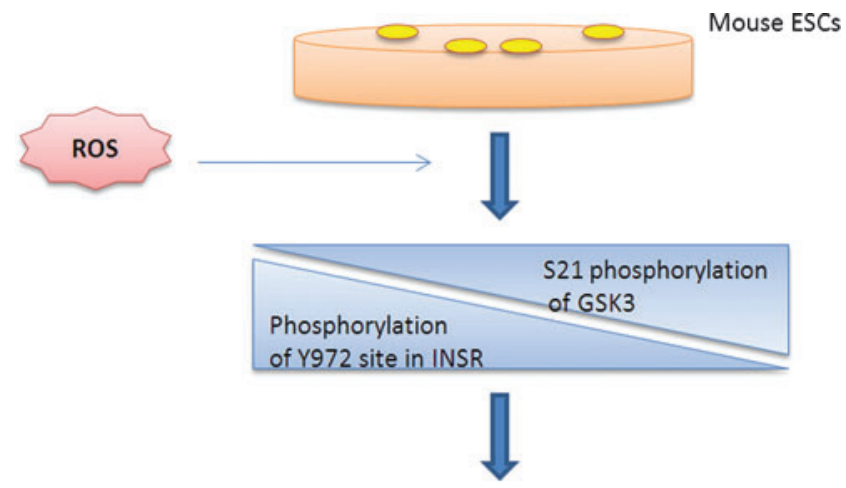

\section{Insulin Resistance Signaling}

FIG. 2. Role of ROS in insulin resistance signaling of ESCs. Single minimally toxic exposure of ROS to murine ESCs led to dysregulated insulin signaling by inducing immediate hypophosphorylation of the insulin receptor (INSR) at Y972 site and a concurrent twofold increase in inhibitory S21 phosphorylation of GSK3. Both these events are associated with insulin resistant signaling. ESCs, embryonic stem cells. To see this illustration in color, the reader is referred to the web version of this article at www.liebertpub.com/ars

significant increases in oncogenic and metastatic pathways and specifically induce insulin signaling, similar to those in insulin-resistant mouse models and diabetic patients (Fig. 2). The hypophosphorylation of insulin receptor at Y972, following such exposure to ROS, provides a direct link between ROS and insulin resistance, as Y972F mutation has been shown to cause severe impairment of the downstream effector IRS-1 adaptor tyrosine phosphorylation, which further impairs the downstream signaling of the insulin pathway (36). Also, a twofold increase in the inhibitory S21 phosphorylation of GSK3 was observed in the mouse ESCs exposed to $\mathrm{H}_{2} \mathrm{O}_{2}$, and it is known that overexpression of GSK3 impairs insulin responsiveness while its knockdown improves insulin action (17). This work lends further credence to the hypothesis that a disease status emanates from a transformed stem cell and underscores the potential role of even a single exposure to ROS to promote this transformation (58).

Although significant attempts have been made during the last decade for directed differentiation of pluripotent stem cells into specialized cell types, the differentiation protocols that have been established so far are toward only a few cell types. The current differentiation has been relying mostly on using the factors associated with embryogenesis. It is therefore important to find alternative factors involved in cell fate changes such as ROS and dissect their roles in the pluripotency and differentiation of stem cells for the purpose of further improving directed differentiation protocols. Recent advances indicate that the participation of ROS-producing nicotinamide adenine dinucleotide phosphate reduced oxidase (NADPH, Nox) system is an important trigger for differentiating ESCs toward the cardiomyocyte lineage $(4,10,72$, $74,76)$. Further elucidation is provided by the finding that high glucose containing medium is an important prerequisite for cardiomyocyte differentiation in ESCs, which probably acts through the glucose-induced production of mitochondrial ROS, which in turn activates the p38 MAPK phosphorelay system via Nox4 (20). NOXs that are a major source of vascular superoxide are one of the many cellular sources of ROS. It has been demonstrated that Nox4-produced $\mathrm{H}_{2} \mathrm{O}_{2}$ plays an important role in the differentiation of mouse ESCs toward the smooth muscle cell (SMC) lineage (90). Autocrine transforming growth factor beta 1 (TGF- $\beta 1$ ) from differentiating mouse ESCs activates Nox4, which then translocates to the nucleus and generates $\mathrm{H}_{2} \mathrm{O}_{2}$. The findings that lend credence to the result that Nox4-mediated SMC differentiation might occur through generation of $\mathrm{H}_{2} \mathrm{O}_{2}$ are that overexpression of Nox4 in the differentiating ESCs increased the $\mathrm{H}_{2} \mathrm{O}_{2}$ generation in a dose-dependent manner, whereas knockdown of Nox4 by siRNA decreased significantly ROS production in the differentiating ESCs. This $\mathrm{H}_{2} \mathrm{O}_{2}$ generation results in upregulation and phosphorylation of the serum response factor (SRF). The phosphorylated SRF translocates to the nucleus and interacts with myocardin to form the SRF/myocardin complex, which in turn is essential for Nox-mediated SMC differentiation (90). Knowledge obtained from these studies will help improve the differentiation condition of ESCs/iPSCs to a more efficient and functional level by modulating the related events and pathways within a certain step of differentiation.

Since maintaining pluripotency and inducing differentiation are highly complex biological processes, it is not uncommon to observe unexpected results especially when another complex factor such as ROS is involved. For example, a recent study showed that FOXO1 from the Forkhead box O transcription factor family is essential for maintaining human ESC pluripotency (102). The pluripotency of ESCs/iPSCs is maintained by some of the key transcription factors, such as OCT4 and NANOG. FoxO proteins are bona fide tumor suppressors (62), and as such promote cell cycle arrest, induce apoptosis, contribute to DNA damage repair, and suppress oxidative stress by modulating genes involved in these processes $(84,101)$. Knockdown of FOXO1, the most abundant FOXO at the messenger RNA level in undifferentiated human ESCs (8), did not however alter the expression of antioxidant enzymes and the ROS levels in human ESCs (102). Further, the antioxidant $\mathrm{N}$-acetyl-cysteine treatment did not impact pluripotency genes in these cells (102), altogether strongly arguing against redox modulation in mediating the effect of FOXO1 on pluripotency. Although other FoxO proteins are essential for the maintenance of stem and progenitor cells, including HSCs and neural stem cells (NSCs), via regulation of ROS (56, $59,68,93,94,102)$, FOXO1 seems critical for regulating human ESC pluripotency by binding to OCT4 and SOX2 regulatory regions (102), not by redox modulation.

Similar findings have been documented for the effect of vitamin $C$ on iPSC reprogramming. Vitamin $C$ that is a common nutrient vital to human health and cofactor of many regulatory enzymes enhances the reprogramming of somatic cells to pluripotent stem cells by partially alleviating senescence that may be a roadblock for reprogramming $(25,78)$. Vitamin C modulates p53 levels and Ink4/ Arf locus during reprogramming $(25,86)$. In addition, histone demethylases Jhdm $1 \mathrm{a} / 1 \mathrm{~b}$ that are key effectors of somatic cell reprogramming are downstream of vitamin C. Jhdm $1 \mathrm{~b}$ specifically accelerates cell cycle progression and suppresses cell senescence during reprogramming by repressing the Ink4/ Arf locus (86). Aberrant epigenetic silencing of the imprinted Dlk1-Dio3 gene cluster is another roadblock in generating iPSCs. By attenuating hypermethylation of Dlk1-Dio3, vitamin C improves iPSC formation (78). Nonetheless, 
the effect of vitamin $C$ does not appear to be related to its antioxidant functions.

\section{Role of ROS in Multipotent ASCs}

The role of ROS has been studied in ASCs, including HSCs, NSCs, and mesenchymal stem cells (MSCs). Foxo3 is essential for the maintenance of HSCs, NSCs, and leukemic stem cells $(56,59,68,93,94)$. HSCs are multipotent stem cells giving rise to the myeloid and lymphoid blood cell types. ROS function as signaling molecules, at physiological level, which can regulate HSC proliferation, differentiation, and mobilization $(35,41,46)$. The osteoblastic niche is the stem cell niche for the quiescent HSCs, which represent the most primitive and the long-term repopulating HSCs $(2,88)$. These endosteal osteoblastic niches are hypoxic $(24,64,89)$, and this hypoxic environment presumably ensures that HSCs are protected from much of the oxidative stress and are better able to maintain the ability of self-renewal $(34,89)$. Thus, ROS production plays an important role in HSC self-renewal. Low-moderate levels of ROS seem to have a role in HSC proliferation, differentiation, and mobilization (Fig. 3a) $(35,41,46)$. This is supported by the findings that HSCs from AKT1/2 doubleknockout mice exhibit a defect in long-term hematopoietic reconstitution (35) and that ROS-dependent HSC proliferation has a vital role in early steps of hematopoietic reconstitution (46), following HSC transplantation. On the other hand, high levels of ROS are toxic for HSCs, as evidenced by the finding that ATM and FoxOs deletions and exposure to total-body irradiation results in increased ROS production, which in turn results in HSC senescence and premature exhaustion (Fig. 3b) $(33,56,82,87,94)$. Also, regenerationinduced intracellular upregulation of ROS resulted in the accumulated and persistent DNA lesions in human HSCs, with ATM and FOXO3a being activated (92). Treatment with antioxidant effectively prevented quantitative and qualitative deterioration of HSC function in vivo and in vitro (30). ROS thus have a role in DNA damage accumulation in human HSCs and have a major impact on stem cell aging. A recent study also shows that CD $34^{+}$HSCs cultured in vitro under low oxygen concentrations produced low level of ROS, and these stem cells displayed good potential for proliferation, differentiation, and reimplantation, while those cultured under high oxygen levels gave the opposite results (30).
Bone marrow MSCs are multipotent stem cells that give rise to adipocytes, chondrocytes, and osteocytes, and occupy the bone marrow along with HSCs. A recent study shows that human MSCs have a high resistance to oxidative-stressinduced death, which correlates with the low level of intracellular reactive species by effective ROS scavenging; constitutive expression of enzymes required to manage oxidative stress, such as SOD1, SOD2, CAT, and GPX1; and high levels of total intracellular glutathione (GSx) (83). The dependence of oxidative stress resistance on high levels of intracellular GSx can be explained by the fact that glutathione plays a vital role in cellular defense against oxidative and nitrosative stress and is also a substrate for quite a few enzymes related to the management of oxidative stress, such as GPX1 (28). Human MSCs also constitutively express methionine sulfoxide reductase A at high levels, which is an enzyme crucial for the repair of oxidized proteins and for the recovery of methionine residues that act as scavengers of oxidants (69). Human MSCs thus possess the main enzymatic and nonenzymatic mechanisms to detoxify the reactive species and to correct oxidative damage of proteome and genome. Another study has investigated the role of ROS in mediating adipocyte differentiation in MSCs (Fig. 4) (37). The findings show that ROS scavengers or RNA interference against Nox4 (NADPH isoform) impairs adipocyte differentiation. Also, CREB acts downstream of ROS in this differentiation pathway, since $\mathrm{H}_{2} \mathrm{O}_{2}$ induces CREB transcriptional activation and CREB has been shown to regulate $\mathrm{C} / \mathrm{EBP} \beta$; ROS may thus act upstream of CREB and subsequently induce $\mathrm{C} / \mathrm{EBP} \beta$ expression in MSCs. NADPH oxidase acts as the source of ROS in MSCs, as evidenced by the observation that Nox4 was downregulated after the induction of differentiation. Also, Nox4 is downregulated in mature adipocytes $(57,75)$. Nox4 thus plays a vital role in adipogenesis from MSCs.

It is known that the level of ROS, which depends critically upon changes in cell density in vitro, are significantly higher in multipotent neural precursor cells from rat hippocampus than that seen in primary or transformed cell lines (48). Higher ROS levels found at lower cell densities were associated with elevated proliferation and increased metabolic activity, while at higher cell densities, intracellular ROS and oxidative damage were reduced along with an increase in the expression of mitochondrial SOD. The in vitro system was also validated by the in vivo finding that DNA-damage-induced depletion of

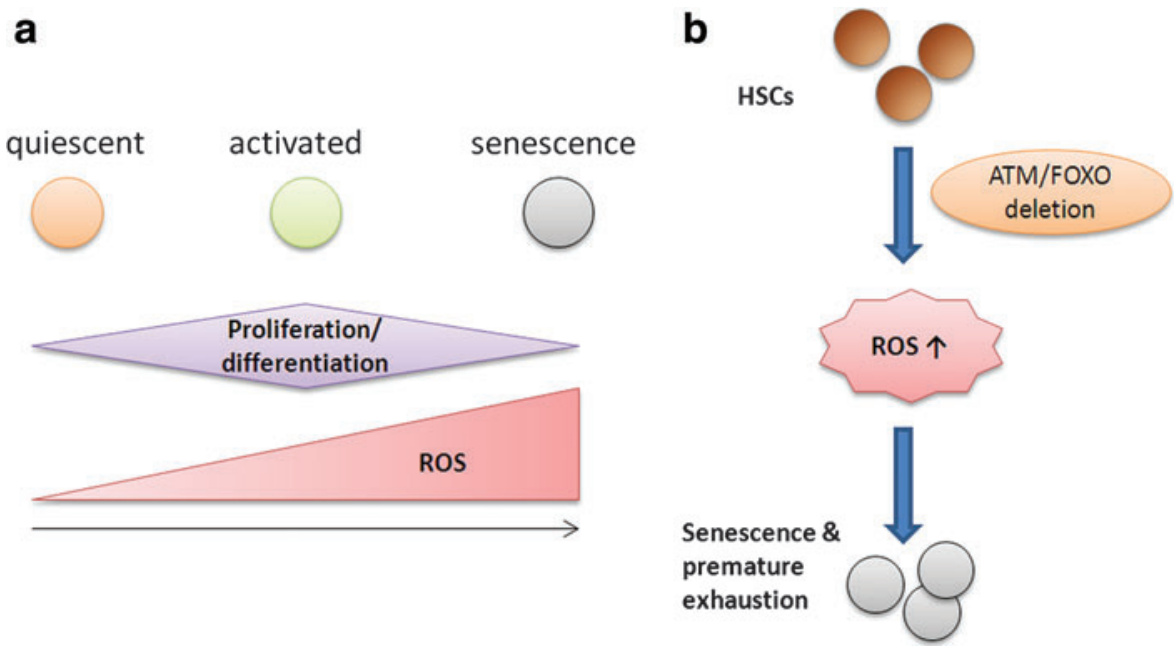

FIG. 3. ROS in HSCs. (a) Lowmoderate levels of ROS support HSC proliferation, differentiation, and mobilization, while high levels of ROS prove to be toxic to HSCs, leading to cell senescence and premature exhaustion. (b) Deletion of ATM and FOXOs from HSCs results in increased ROS, leading up to cell senescence and premature exhaustion of HSCs. HSCs, hematopoietic stem cells. To see this illustration in color, the reader is referred to the web version of this article at www.liebertpub.com/ars 
FIG. 4. ROS mediate adipocyte differentiation from MSCs. Nox4, a NADPH oxidase isoform, is one of the sources of ROS in rat MSCs and is essential during differentiating MSCs to adipocytes. ROS is blocked on silencing Nox4, or addition of NAC antioxidant or PrxII ROS scavenger, which in turn does not activate CREB, thus blocking adipocyte differentiation. MSCs, mesenchymal stem cells. To see this illustration in color, the reader is referred to the web version of this article at www.liebertpub.com/ars

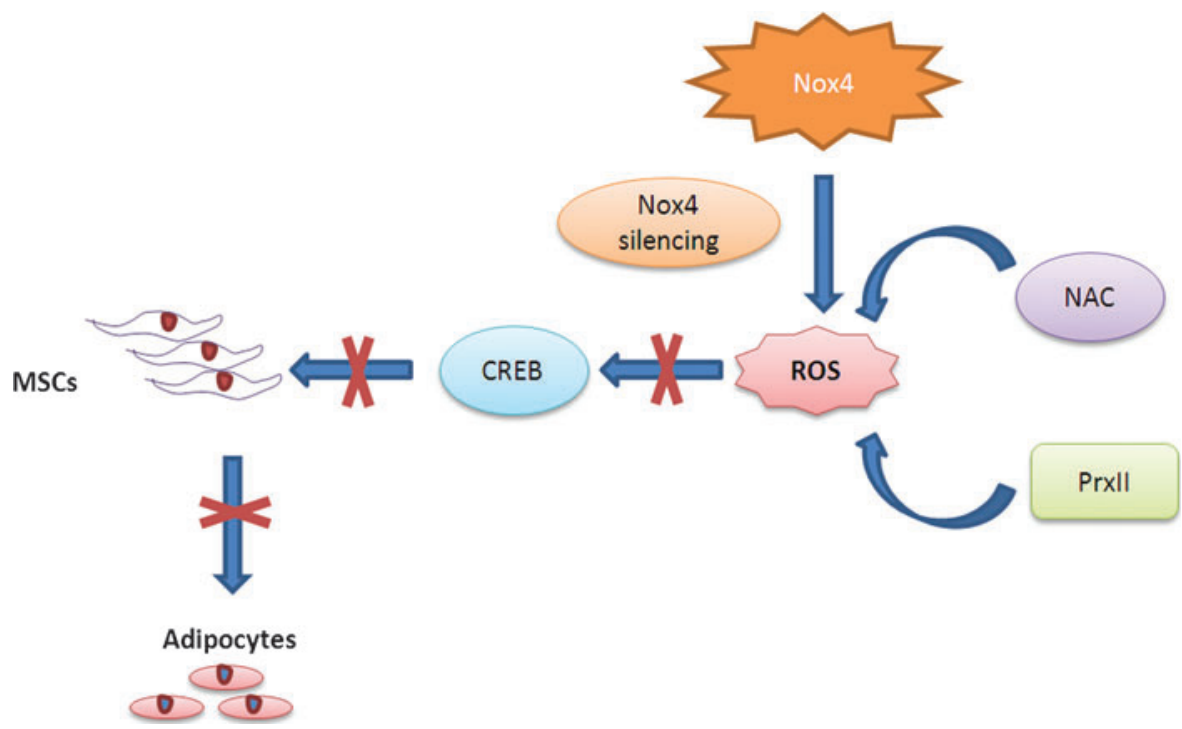

neural precursor cells in the subgranular zone of mice also showed increased ROS and altered proliferation. Thus, neural precursor cells are predisposed to redox regulation. NSCs like ESCs have enhanced antioxidant capacity, and they possess a superior resistance to oxidative-stress-mediated cell death (53, 54). FOXO proteins seem to have a role in cellular redox regulation, since when the FOXO genes are deleted from NSCs and neural progenitor cells, the antioxidant defenses are significantly depleted and endogenous ROS levels are increased, leading to an initial hyperproliferation of NSCs, followed by a buildup of toxic levels of ROS that may have a role in the premature senescence observed later $(61,68)$. Also, it has been observed that antioxidant treatments, such as NOX inhibition, inhibit hippocampal progenitor proliferation (98). A novel ROS-regulating gene Prdm16 when deleted results in brain undergrowth (15). This gene has also been shown to regulate cellular ROS levels in HSCs by specifically altering mitochondrial ROS and not NADPH-oxidase-generated ROS (51). Prdm16 is also required to regulate ROS levels in primi- tive hematopoietic progenitors, although loss of Prdm16 appeared to decrease ROS levels in these cells, in contrast to the nervous system, where Prdm16 promotes $\mathrm{Hg} f$ expression in NSCs/progenitor cells and HGF in turn regulates ROS levels in these cells, and increased ROS levels contribute to the defects in NSC/progenitor cell function in Prdm16 ${ }^{\text {LacZ/LacZ }}$ mice. Hence, the contradictory effects of Prdm16-mediated ROS regulation observed in NSCs may be related to the endogenous source of ROS and the cellular compartment in which they act. Definitive NSCs may be expected to have a lower endogenous ROS status than that of highly proliferative, transient amplifying progenitors, since the adult NSCs are thought to be in a quiescent state in vivo (23). However, recent data suggest that NSCs have a higher level of endogenous ROS levels in vivo, which may have a role in maintaining the proliferation of progenitor cells in the neurogenic niche (Fig. 5), and that NADPH oxidase and the PI3k/Akt signaling pathway have a prominent role in regulating these ROS levels (44). These high levels of ROS could reflect the "activated"
FIG. 5. ROS in NSCs. (a) NSCs remain quiescent at low ROS levels, and as the ROS levels increase, the cells become proliferative. High ROS levels lead to cell senescence and death. (b) Also, inhibition of normal endogenous ROS production by Nox inhibition or mutation negatively regulates the $\mathrm{PI} 3 \mathrm{~K} / \mathrm{Akt}$ pathway and NSC function. NSCs, neural stem cells. To see this illustration in color, the reader is referred to the web version of this article at www.liebertpub.com/ars

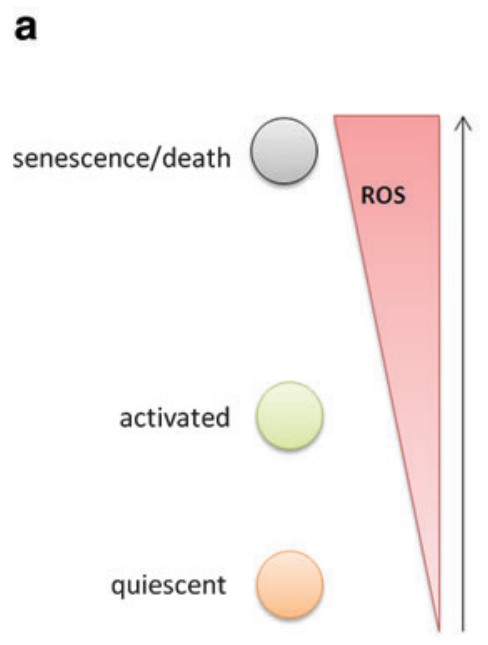

b

RTKs
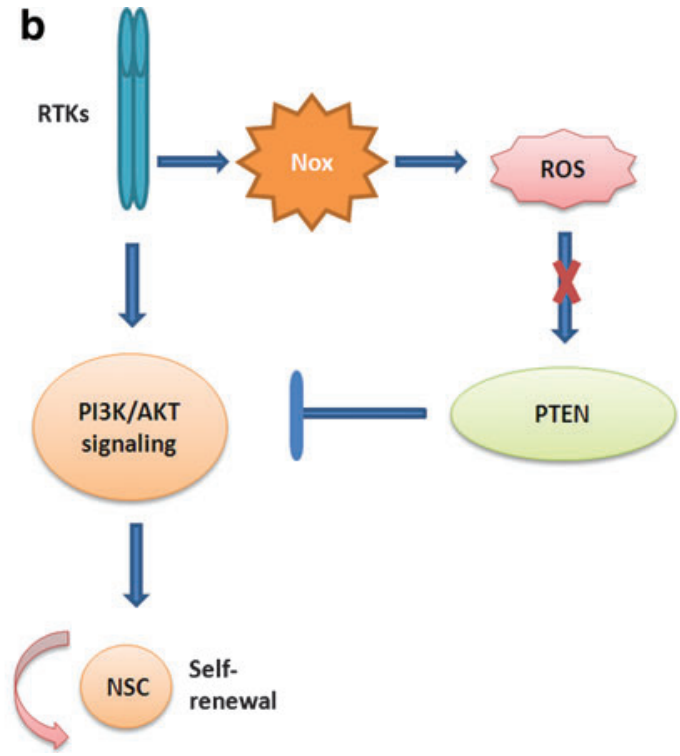
state in the cells as result of removal from their niche. The data suggests that in order to maintain normal levels of neurogenesis, the NSCs must need to be able to increase ROS levels when required for cell division but does not rule out the possibility that NSCs maintain a low ROS state in vivo when they are in a quiescent state. ROS have also proved to be of major importance in neuronal differentiation, promoted by the NADPH oxidase activity in MSCs via elevating ROS levels (85).

\section{Role of Hypoxia in Pluripotent Stem Cells}

Hypoxia, defined as low oxygen levels, though commonly believed to be merely pathology related, also plays a major role in physiological processes. It is involved in embryogenesis, importantly signaling processes that regulate the proliferation and differentiation of stem cells $(12,77)$. Hypoxia inducible factor (HIF) is a well-known transcription factor associated with acute and chronic response to hypoxia (45, 65). HIF is an $\alpha / \beta$ heterodimeric protein that binds to the hypoxia response elements on DNA and thus modulates multiple genes involved in the cellular responses to hypoxia. Evidence suggests that acute hypoxia also contributes to the generation of ROS, though this is still controversial. Hypoxia appears to stimulate mitochondria to produce ROS at complex III of the mitochondrial respiratory chain, and this in turn contributes to the hypoxia-induced gene expression changes (43). Hypoxia-ischemia and reperfusion generates ROS; especially, when oxygen supply is re-established (i.e., reperfusion), the cellular antioxidant machinery is not able to buffer the sudden surge in ROS production (22). On the other hand, ROS can activate and/or stabilize HIF, probably through the action of prolyl hydroxylases, thus participating in the activation of the homeostatic responses to hypoxia $(9,43,100)$.

Much evidence suggests the role of HIF- $1 \alpha$ and HIF- $2 \alpha$ in maintaining pluripotency of human ESCs, specifically by activating OCT4 expression (19, 27, 32). Also, culturing human ESCs by constant hypoxic conditions may maintain pluripotency by sustaining Notch activation (67). Recent research data also show that using hypoxic conditions $\left(5 \% \mathrm{O}_{2}\right)$ increases the efficiency of generation of iPSCs from mouse MEFs using OCT3/4, Sox2, and Klf4 retroviral transduction, as well as with nonviral vectors, such as plasmid expression vectors or piggyback transposition system (99). Hypoxia also shows increased efficiency in the derivation of human iPSCs from dermal fibroblasts on transduction of OCT3/4, Sox2, Klf4, and c-Myc retroviral vectors (99). Thus, hypoxia seems to have a role in not only inducing but also sustaining pluripotency in stem cells.

\section{Conclusions}

All stem cells, whether pluripotent or multipotent, seem to maintain their genomic identity by maintaining low intracellular ROS levels. This is enabled by antioxidant defense, such as high expression of antioxidant genes, enhanced DNA double-strand break repair, and expression of heat shock proteins. Importantly, the pluripotent stem cells also have a reduced mitochondrial copy number, which keeps the ROS production in check. Both pluripotent and multipotent stem cells thus possess enzymatic and nonenzymatic mechanisms for detoxification of ROS and to correct oxidative damage to the genome as well as the proteome. Although context

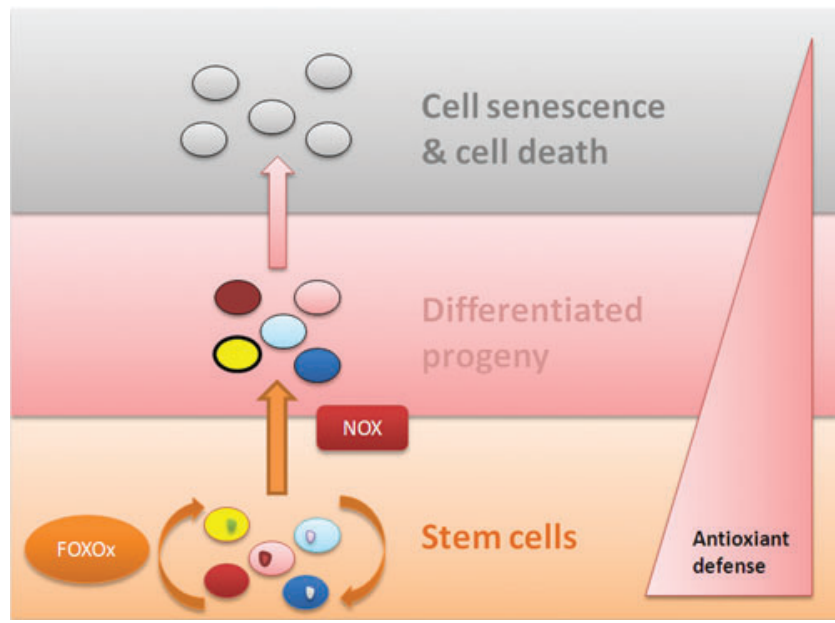

FIG. 6. Antioxidant defense in stem cells. Antioxidant defense mechanisms are vital for maintaining stem cell identity. As stem cells become differentiated, the defense level decreases. FOXO proteins have important role in maintaining stemness, while NOX has been implicated in differentiation of stem cells. As the cells become differentiated, ROS start accumulating, followed by cell senescence and death. NOX, NADPH oxidase. To see this illustration in color, the reader is referred to the web version of this article at www.liebertpub.com/ars

dependent and somewhat varied among different stem cell types, the correlation does exist between antioxidant defense level and stem cell fate change (i.e., proliferation, differentiation, and death) (Fig. 6). FOXO proteins have an essential role in maintaining stem cell identity, while the Nox system is of special importance in the differentiation of stem cells in not only embryonic but also MSCs and NSCs. Regulation of ROS thus has a vital role in maintaining "stemness" and differentiation of the stem cells, as well as in progression of stem-cellassociated diseases.

\section{Acknowledgments}

This work was supported by NIH grant R21AA020020 and by MSCRF grants 2010-MSCRFII-0101-00.

\section{References}

1. Aasen T, Raya A, Barrero MJ, Garreta E, Consiglio A, Gonzalez F, Vassena R, Bilic J, Pekarik V, Tiscornia G, Edel $\mathrm{M}$, Boue S, and Izpisua Belmonte JC. Efficient and rapid generation of induced pluripotent stem cells from human keratinocytes. Nat Biotechnol 26: 1276-1284, 2008.

2. Arai F, and Suda T. Maintenance of quiescent hematopoietic stem cells in the osteoblastic niche. Ann N Y Acad Sci 1106: 41-53, 2007.

3. Armstrong L, Tilgner K, Saretzki G, Atkinson SP, Stojkovic M, Moreno R, Przyborski S, and Lako M. Human induced pluripotent stem cell lines show stress defense mechanisms and mitochondrial regulation similar to those of human embryonic stem cells. Stem Cells 28: 661-673, 2010.

4. Ateghang B, Wartenberg M, Gassmann M, and Sauer H. Regulation of cardiotrophin-1 expression in mouse embryonic stem cells by HIF-1alpha and intracellular reactive oxygen species. J Cell Sci 119: 1043-1052, 2006. 
5. Balaban RS, Nemoto S, and Finkel T. Mitochondria, oxidants, and aging. Cell 120: 483-495, 2005.

6. Berretta N, Freestone PS, Guatteo E, de Castro D, Geracitano R, Bernardi G, Mercuri NB, and Lipski J. Acute effects of 6-hydroxydopamine on dopaminergic neurons of the rat substantia nigra pars compacta in vitro. Neurotoxicology 26: 869-881, 2005.

7. Bevilacqua A, Kinnunen LH, Bevilacqua S, and Mangia F. Stage-specific regulation of murine Hsp68 gene promoter in preimplantation mouse embryos. Dev Biol 170: 467-478, 1995.

8. Brandenberger R, Wei H, Zhang S, Lei S, Murage J, Fisk GJ, Li Y, Xu C, Fang R, Guegler K, Rao MS, Mandalam R, Lebkowski J, and Stanton LW. Transcriptome characterization elucidates signaling networks that control human ES cell growth and differentiation. Nat Biotechnol 22: 707716, 2004.

9. Bruick RK, and McKnight SL. A conserved family of prolyl4-hydroxylases that modify HIF. Science 294: 1337-1340, 2001.

10. Buggisch M, Ateghang B, Ruhe C, Strobel C, Lange S, Wartenberg M, and Sauer H. Stimulation of ES-cell-derived cardiomyogenesis and neonatal cardiac cell proliferation by reactive oxygen species and NADPH oxidase. J Cell Sci 120: 885-894, 2007.

11. Carette J, Lehnert S, and Chow TY. Implication of PBP74/ mortalin/GRP75 in the radio-adaptive response. Int J Radiat Biol 78: 183-190, 2002.

12. Chalmers AD, Lachani K, Shin Y, Sherwood V, Cho KW, and Papalopulu N. Grainyhead-like 3, a transcription factor identified in a microarray screen, promotes the specification of the superficial layer of the embryonic epidermis. Mech Dev 123: 702-718, 2006.

13. Choi SM, Kim Y, Liu H, Chaudhari P, Ye Z, and Jang YY. Liver engraftment potential of hepatic cells derived from patient-specific induced pluripotent stem cells. Cell Cycle 10: 2423-2427, 2011.

14. Choi SM, Liu H, Chaudhari P, Kim Y, Cheng L, Feng J, Sharkis S, Ye Z, and Jang YY. Reprogramming of EBVimmortalized B-lymphocyte cell lines into induced pluripotent stem cells. Blood 118: 1801-1805, 2011.

15. Chuikov S, Levi BP, Smith ML, and Morrison SJ. Prdm16 promotes stem cell maintenance in multiple tissues, partly by regulating oxidative stress. Nat Cell Biol 12: 999-1006, 2010.

16. Chun YS, Chaudhari P, and Jang YY. Applications of patient-specific induced pluripotent stem cells; focused on disease modeling, drug screening and therapeutic potentials for liver disease. Int J Biol Sci 6: 796-805, 2010.

17. Ciaraldi TP, Nikoulina SE, Bandukwala RA, Carter L, and Henry RR. Role of glycogen synthase kinase-3 alpha in insulin action in cultured human skeletal muscle cells. Endocrinology 148: 4393-4399, 2007.

18. Cohen G, and Hochstein P. Glutathione peroxidase: the primary agent for the elimination of hydrogen peroxide in erythrocytes. Biochemistry 2: 1420-1428, 1963.

19. Covello KL, Kehler J, Yu H, Gordan JD, Arsham AM, Hu CJ, Labosky PA, Simon MC, and Keith B. HIF-2alpha regulates Oct-4: effects of hypoxia on stem cell function, embryonic development, and tumor growth. Genes Dev 20: 557-570, 2006.

20. Crespo FL, Sobrado VR, Gomez L, Cervera AM, and McCreath KJ. Mitochondrial reactive oxygen species mediate cardiomyocyte formation from embryonic stem cells in high glucose. Stem Cells 28: 1132-1142, 2010.

21. Ding YM, Jaumotte JD, Signore AP, and Zigmond MJ. Effects of 6-hydroxydopamine on primary cultures of substantia nigra: specific damage to dopamine neurons and the impact of glial cell line-derived neurotrophic factor. J Neurochem 89: 776-787, 2004.

22. Dirnagl U, Becker K, and Meisel A. Preconditioning and tolerance against cerebral ischaemia: from experimental strategies to clinical use. Lancet Neurol 8: 398-412, 2009.

23. Doetsch F, Garcia-Verdugo JM, and Alvarez-Buylla A. Cellular composition and three-dimensional organization of the subventricular germinal zone in the adult mammalian brain. J Neurosci 17: 5046-5061, 1997.

24. Eliasson P, and Jonsson JI. The hematopoietic stem cell niche: low in oxygen but a nice place to be. J Cell Physiol 222: 17-22, 2010.

25. Esteban M, Wang T, Qin B, Yang J, Qin D, Cai J, Li W, Weng Z, Chen J, Ni S, Chen K, Li Y, Liu X, Xu J, Zhang S, Li F, He W, Labuda K, Song Y, Peterbauer A, Wolbank S, Redl $\mathrm{H}$, Zhong M, Cai D, Zeng L, and Pei D. Vitamin C enhances the generation of mouse and human induced pluripotent stem cells. Cell Stem Cell 6: 71-79, 2010.

26. Fan J, Robert C, Jang YY, Liu H, Sharkis S, Baylin SB, and Rassool FV. Human induced pluripotent cells resemble embryonic stem cells demonstrating enhanced levels of DNA repair and efficacy of nonhomologous end-joining. Mutat Res 713: 8-17, 2011.

27. Forristal CE, Wright KL, Hanley NA, Oreffo RO, and Houghton FD. Hypoxia inducible factors regulate pluripotency and proliferation in human embryonic stem cells cultured at reduced oxygen tensions. Reproduction 139: 85-97, 2010.

28. Franco R, Schoneveld OJ, Pappa A, and Panayiotidis MI. The central role of glutathione in the pathophysiology of human diseases. Arch Physiol Biochem 113: 234-258, 2007.

29. Gurbuxani S, Schmitt E, Cande C, Parcellier A, Hammann A, Daugas E, Kouranti I, Spahr C, Pance A, Kroemer G, and Garrido C. Heat shock protein 70 binding inhibits the nuclear import of apoptosis-inducing factor. Oncogene 22: 6669-6678, 2003.

30. Hao Y, Cheng D, Ma Y, Zhou W, and Wang Y. The relationship between oxygen concentration, reactive oxygen species and the biological characteristics of human bone marrow hematopoietic stem cells. Transplant Proc 43: 2755-2761, 2011.

31. Hofmann B, Hecht HJ, and Flohe L. Peroxiredoxins. Biol Chem 383: 347-364, 2002.

32. Hu CJ, Iyer S, Sataur A, Covello KL, Chodosh LA, and Simon MC. Differential regulation of the transcriptional activities of hypoxia-inducible factor 1 alpha (HIF-1alpha) and HIF-2alpha in stem cells. Mol Cell Biol 26: 3514-3526, 2006.

33. Ito K, Takubo K, Arai F, Satoh H, Matsuoka S, Ohmura M, Naka K, Azuma M, Miyamoto K, Hosokawa K, Ikeda Y, Mak TW, Suda T, and Hirao A. Regulation of reactive oxygen species by Atm is essential for proper response to DNA double-strand breaks in lymphocytes. J Immunol 178: 103-110, 2007.

34. Jang YY, and Sharkis SJ. A low level of reactive oxygen species selects for primitive hematopoietic stem cells that may reside in the low-oxygenic niche. Blood 110: 3056-3063, 2007. 
35. Juntilla MM, Patil VD, Calamito M, Joshi RP, Birnbaum MJ, and Koretzky GA. AKT1 and AKT2 maintain hematopoietic stem cell function by regulating reactive oxygen species. Blood 115: 4030-4038, 2010.

36. Kaburagi $Y$, Momomura K, Yamamoto-Honda R, Tobe K, Tamori Y, Sakura H, Akanuma Y, Yazaki Y, and Kadowaki T. Site-directed mutagenesis of the juxtamembrane domain of the human insulin receptor. J Biol Chem 268: 1661016622, 1993.

37. Kanda Y, Hinata T, Kang SW, and Watanabe Y. Reactive oxygen species mediate adipocyte differentiation in mesenchymal stem cells. Life Sci 89: 250-258, 2011.

38. Kaul SC, Taira K, Pereira-Smith OM, and Wadhwa R. Mortalin: present and prospective. Exp Gerontol 37: 11571164, 2002.

39. Kaula SC, Reddelb RR, Sugiharac T, Mitsuia Y, and Wadhwac R. Inactivation of p53 and life span extension of human diploid fibroblasts by mot-2. FEBS Lett 474: 159164, 2000.

40. Kim JB, Sebastiano V, Wu G, Arauzo-Bravo MJ, Sasse P, Gentile L, Ko K, Ruau D, Ehrich M, van den Boom D, Meyer J, Hubner K, Bernemann C, Ortmeier C, Zenke M, Fleischmann BK, Zaehres H, and Scholer HR. Oct4-induced pluripotency in adult neural stem cells. Cell 136: 411-419, 2009.

41. Kinder M, Wei C, Shelat SG, Kundu M, Zhao L, Blair IA, and Pure E. Hematopoietic stem cell function requires 12/15-lipoxygenase-dependent fatty acid metabolism. Blood 115: 5012-5022, 2010.

42. Kirby K, Hu J, Hilliker AJ, and Phillips JP. RNA interference-mediated silencing of Sod2 in Drosophila leads to early adult-onset mortality and elevated endogenous oxidative stress. Proc Natl Acad Sci U S A 99: 16162-16167, 2002.

43. Klimova T, and Chandel NS. Mitochondrial complex III regulates hypoxic activation of HIF. Cell Death Differ 15: 660-666, 2008.

44. Le Belle JE, Orozco NM, Paucar AA, Saxe JP, Mottahedeh J, Pyle AD, Wu H, and Kornblum HI. Proliferative neural stem cells have high endogenous ROS levels that regulate self-renewal and neurogenesis in a PI3K/Akt-dependant manner. Cell Stem Cell 8: 59-71, 2011.

45. Lendahl U, Lee KL, Yang H, and Poellinger L. Generating specificity and diversity in the transcriptional response to hypoxia. Nat Rev Genet 10: 821-832, 2009.

46. Lewandowski D, Barroca V, Duconge F, Bayer J, Van Nhieu JT, Pestourie C, Fouchet P, Tavitian B, and Romeo $\mathrm{PH}$. In vivo cellular imaging pinpoints the role of reactive oxygen species in the early steps of adult hematopoietic reconstitution. Blood 115: 443-452, 2010.

47. Li HY, Chien Y, Chen YJ, Chen SF, Chang YL, Chiang CH, Jeng SY, Chang CM, Wang ML, Chen LK, Hung SI, Huo TI, Lee SD, and Chiou SH. Reprogramming induced pluripotent stem cells in the absence of c-Myc for differentiation into hepatocyte-like cells. Biomaterials 32: 5994-6005, 2011.

48. Limoli CL, Rola R, Giedzinski E, Mantha S, Huang TT, and Fike JR. Cell-density-dependent regulation of neural precursor cell function. Proc Natl Acad Sci U S A 101: 1605216057, 2004.

49. Liu H, Kim Y, Sharkis S, Marchionni L, and Jang YY. In vivo liver regeneration potential of human induced pluripotent stem cells from diverse origins. Sci Transl Med 3: 82ra39, 2011.
50. Liu H, Ye Z, Kim Y, Sharkis S, and Jang YY. Generation of endoderm-derived human induced pluripotent stem cells from primary hepatocytes. Hepatology 51: 1810-1819, 2010.

51. Liu J, Cao L, Chen J, Song S, Lee IH, Quijano C, Liu H, Keyvanfar K, Chen H, Cao LY, Ahn BH, Kumar NG, Rovira, II, Xu XL, van Lohuizen M, Motoyama N, Deng CX, and Finkel T. Bmi1 regulates mitochondrial function and the DNA damage response pathway. Nature 459: 387-392, 2009.

52. Loh YH, Agarwal S, Park IH, Urbach A, Huo H, Heffner GC, Kim K, Miller JD, Ng K, and Daley GQ. Generation of induced pluripotent stem cells from human blood. Blood 113: 5476-5479, 2009.

53. Madhavan L, Ourednik V, and Ourednik J. Increased "vigilance" of antioxidant mechanisms in neural stem cells potentiates their capability to resist oxidative stress. Stem Cells 24: 2110-2119, 2006.

54. Madhavan L, Ourednik V, and Ourednik J. Neural stem/ progenitor cells initiate the formation of cellular networks that provide neuroprotection by growth factor-modulated antioxidant expression. Stem Cells 26: 254-265, 2008.

55. Michiels C, Raes M, Toussaint O, and Remacle J. Importance of Se-glutathione peroxidase, catalase, and $\mathrm{Cu}$ / Zn-SOD for cell survival against oxidative stress. Free Radic Biol Med 17: 235-248, 1994.

56. Miyamoto K, Araki KY, Naka K, Arai F, Takubo K, Yamazaki S, Matsuoka S, Miyamoto T, Ito K, Ohmura M, Chen C, Hosokawa K, Nakauchi H, Nakayama K, Nakayama KI, Harada M, Motoyama N, Suda T, and Hirao A. Foxo3a is essential for maintenance of the hematopoietic stem cell pool. Cell Stem Cell 1: 101-112, 2007.

57. Mouche S, Mkaddem SB, Wang W, Katic M, Tseng YH, Carnesecchi S, Steger K, Foti M, Meier CA, Muzzin P, Kahn CR, Ogier-Denis E, and Szanto I. Reduced expression of the NADPH oxidase NOX4 is a hallmark of adipocyte differentiation. Biochim Biophys Acta 1773: 1015-1027, 2007.

58. Mouzannar R, McCafferty J, Benedetto G, and Richardson C. Transcriptional and phospho-proteomic screens reveal stem cell activation of insulin-resistance and transformation pathways following a single minimally toxic episode of ROS. Int J Genomics Proteomics 2: 34-49, 2011.

59. Naka K, Hoshii T, Muraguchi T, Tadokoro Y, Ooshio T, Kondo Y, Nakao S, Motoyama N, and Hirao A. TGF-betaFOXO signalling maintains leukaemia-initiating cells in chronic myeloid leukaemia. Nature 463: 676-680, 2010.

60. Nguyen HN, Byers B, Cord B, Shcheglovitov A, Byrne J, Gujar P, Kee K, Schule B, Dolmetsch RE, Langston W, Palmer TD, and Pera RR. LRRK2 mutant iPSC-derived DA neurons demonstrate increased susceptibility to oxidative stress. Cell Stem Cell 8: 267-280, 2011.

61. Paik JH, Ding Z, Narurkar R, Ramkissoon S, Muller F, Kamoun WS, Chae SS, Zheng H, Ying H, Mahoney J, Hiller D, Jiang S, Protopopov A, Wong WH, Chin L, Ligon KL, and DePinho RA. FoxOs cooperatively regulate diverse pathways governing neural stem cell homeostasis. Cell Stem Cell 5: 540-553, 2009.

62. Paik JH, Kollipara R, Chu G, Ji H, Xiao Y, Ding Z, Miao L, Tothova Z, Horner JW, Carrasco DR, Jiang S, Gilliland DG, Chin L, Wong WH, Castrillon DH, and DePinho RA. FoxOs are lineage-restricted redundant tumor suppressors and regulate endothelial cell homeostasis. Cell 128: 309-323, 2007.

63. Pan L, Chen S, Weng C, Call G, Zhu D, Tang H, Zhang N, and Xie T. Stem cell aging is controlled both intrinsically 
and extrinsically in the Drosophila ovary. Cell Stem Cell 1: 458-469, 2007.

64. Parmar K, Mauch P, Vergilio JA, Sackstein R, and Down JD. Distribution of hematopoietic stem cells in the bone marrow according to regional hypoxia. Proc Natl Acad Sci U S A 104: 5431-5436, 2007.

65. Patel SA, and Simon MC. Biology of hypoxia-inducible factor-2alpha in development and disease. Cell Death Differ 15: 628-634, 2008.

66. Pervaiz S, Taneja R, and Ghaffari S. Oxidative stress regulation of stem and progenitor cells. Antioxid Redox Signal 11: 2777-2789, 2009.

67. Prasad SM, Czepiel M, Cetinkaya C, Smigielska K, Weli SC, Lysdahl H, Gabrielsen A, Petersen K, Ehlers N, Fink T, Minger SL, and Zachar V. Continuous hypoxic culturing maintains activation of Notch and allows long-term propagation of human embryonic stem cells without spontaneous differentiation. Cell Prolif 42: 63-74, 2009.

68. Renault VM, Rafalski VA, Morgan AA, Salih DA, Brett JO, Webb AE, Villeda SA, Thekkat PU, Guillerey C, Denko NC, Palmer TD, Butte AJ, and Brunet A. FoxO3 regulates neural stem cell homeostasis. Cell Stem Cell 5: 527-539, 2009.

69. Salmon AB, Perez VI, Bokov A, Jernigan A, Kim G, Zhao H, Levine RL, and Richardson A. Lack of methionine sulfoxide reductase $\mathrm{A}$ in mice increases sensitivity to oxidative stress but does not diminish life span. FASEB J 23: 3601-3608, 2009.

70. Saretzki G, Armstrong L, Leake A, Lako M, and von Zglinicki T. Stress defense in murine embryonic stem cells is superior to that of various differentiated murine cells. Stem Cells 22: 962-971, 2004.

71. Sauer H, and Oertel WH. Progressive degeneration of nigrostriatal dopamine neurons following intrastriatal terminal lesions with 6-hydroxydopamine: a combined retrograde tracing and immunocytochemical study in the rat. Neuroscience 59: 401-415, 1994.

72. Sauer H, Rahimi G, Hescheler J, and Wartenberg M. Role of reactive oxygen species and phosphatidylinositol 3-kinase in cardiomyocyte differentiation of embryonic stem cells. FEBS Lett 476: 218-223, 2000.

73. Schafer FQ, and Buettner GR. Redox environment of the cell as viewed through the redox state of the glutathione disulfide/glutathione couple. Free Radic Biol Med 30: 11911212, 2001.

74. Schmelter M, Ateghang B, Helmig S, Wartenberg M, and Sauer H. Embryonic stem cells utilize reactive oxygen species as transducers of mechanical strain-induced cardiovascular differentiation. FASEB J 20: 1182-1184, 2006.

75. Schroder K, Wandzioch K, Helmcke I, and Brandes RP. Nox 4 acts as a switch between differentiation and proliferation in preadipocytes. Arterioscler Thromb Vasc Biol 29: 239-245, 2009.

76. Sharifpanah F, Wartenberg M, Hannig M, Piper HM, and Sauer H. Peroxisome proliferator-activated receptor alpha agonists enhance cardiomyogenesis of mouse ES cells by utilization of a reactive oxygen species-dependent mechanism. Stem Cells 26: 64-71, 2008.

77. Simon MC, and Keith B. The role of oxygen availability in embryonic development and stem cell function. Nat Rev Mol Cell Biol 9: 285-296, 2008.

78. Stadtfeld M, Apostolou E, Ferrari F, Choi J, Walsh RM, Chen T, Ooi SS, Kim SY, Bestor TH, Shioda T, Park PJ, and Hochedlinger K. Ascorbic acid prevents loss of Dlk1-Dio3 imprinting and facilitates generation of all-iPS cell mice from terminally differentiated B cells. Nat Genet 44: 398405, S391-392, 2012.

79. Stromer T, Ehrnsperger M, Gaestel M, and Buchner J. Analysis of the interaction of small heat shock proteins with unfolding proteins. J Biol Chem 278: 18015-18021, 2003.

80. Sun QA, Kirnarsky L, Sherman S, and Gladyshev VN. Selenoprotein oxidoreductase with specificity for thioredoxin and glutathione systems. Proc Natl Acad Sci U S A 98: 36733678, 2001.

81. Takahashi K, and Yamanaka S. Induction of pluripotent stem cells from mouse embryonic and adult fibroblast cultures by defined factors. Cell 126: 663-676, 2006.

82. Tothova Z, Kollipara R, Huntly BJ, Lee BH, Castrillon DH, Cullen DE, McDowell EP, Lazo-Kallanian S, Williams IR, Sears C, Armstrong SA, Passegue E, DePinho RA, and Gilliland DG. FoxOs are critical mediators of hematopoietic stem cell resistance to physiologic oxidative stress. Cell 128: 325-339, 2007.

83. Valle-Prieto A, and Conget PA. Human mesenchymal stem cells efficiently manage oxidative stress. Stem Cells Dev 19: 1885-1893, 2010.

84. van den Berg MC, and Burgering BM. Integrating opposing signals toward Forkhead box O. Antioxid Redox Signal 14: 607-621, 2011.

85. Wang N, Xie K, Huo S, Zhao J, Zhang S, and Miao J. Suppressing phosphatidylcholine-specific phospholipase C and elevating ROS level, NADPH oxidase activity and $\mathrm{Rb}$ level induced neuronal differentiation in mesenchymal stem cells. J Cell Biochem 100: 1548-1557, 2007.

86. Wang T, Chen K, Zeng X, Yang J, Wu Y, Shi X, Qin B, Zeng L, Esteban MA, Pan G, and Pei D. The histone demethylases Jhdm $1 \mathrm{a} / 1 \mathrm{~b}$ enhance somatic cell reprogramming in a vitamin-C-dependent manner. Cell Stem Cell 9: 575-587, 2011.

87. Wang Y, Liu L, Pazhanisamy SK, Li H, Meng A, and Zhou D. Total body irradiation causes residual bone marrow injury by induction of persistent oxidative stress in murine hematopoietic stem cells. Free Radic Biol Med 48: 348-356, 2010.

88. Wilson A, Oser GM, Jaworski M, Blanco-Bose WE, Laurenti E, Adolphe C, Essers MA, Macdonald HR, and Trumpp A. Dormant and self-renewing hematopoietic stem cells and their niches. Ann N Y Acad Sci 1106: 64-75, 2007.

89. Winkler IG, Barbier V, Wadley R, Zannettino AC, Williams S, and Levesque JP. Positioning of bone marrow hematopoietic and stromal cells relative to blood flow in vivo: serially reconstituting hematopoietic stem cells reside in distinct nonperfused niches. Blood 116: 375-385, 2010.

90. Xiao Q, Luo Z, Pepe AE, Margariti A, Zeng L, and Xu Q. Embryonic stem cell differentiation into smooth muscle cells is mediated by Nox4-produced $\mathrm{H}_{2} \mathrm{O}_{2}$. Am J Physiol Cell Physiol 296: C711-C723, 2009.

91. Xu J, Xiao HH, and Sartorelli AC. Attenuation of the induced differentiation of HL-60 leukemia cells by mitochondrial chaperone HSP70. Oncol Res 11: 429-435, 1999.

92. Yahata T, Takanashi T, Muguruma Y, Ibrahim AA, Matsuzawa $H$, Uno T, Sheng $Y$, Onizuka M, Ito M, Kato S, and Ando K. Accumulation of oxidative DNA damage restricts the self-renewal capacity of human hematopoietic stem cells. Blood 118: 2941-2950, 2011. 
93. Yalcin S, Marinkovic D, Mungamuri SK, Zhang X, Tong W, Sellers R, and Ghaffari S. ROS-mediated amplification of $\mathrm{AKT} / \mathrm{mTOR}$ signalling pathway leads to myeloproliferative syndrome in Foxo3(-/-) mice. EMBO J 29: 4118-4131, 2010.

94. Yalcin S, Zhang X, Luciano JP, Mungamuri SK, Marinkovic D, Vercherat C, Sarkar A, Grisotto M, Taneja R, and Ghaffari S. Foxo3 is essential for the regulation of ataxia telangiectasia mutated and oxidative stress-mediated homeostasis of hematopoietic stem cells. J Biol Chem 283: 25692-25705, 2008.

95. Ye Z, Liu CF, and Jang YY. Hematopoietic cells as sources for patient-specific iPSCs and disease modeling. Cell Cycle 10: 2840-2844, 2011.

96. Ye Z, Zhan H, Mali P, Dowey S, Williams DM, Jang YY, Dang CV, Spivak JL, Moliterno AR, and Cheng L. Humaninduced pluripotent stem cells from blood cells of healthy donors and patients with acquired blood disorders. Blood 114: 5473-5480, 2009.

97. Yi MJ, Park SH, Cho HN, Yong Chung H, Kim JI, Cho CK, Lee SJ, and Lee YS. Heat-shock protein 25 (Hspb1) regulates manganese superoxide dismutase through activation of Nfkb (NF-kappaB). Radiat Res 158: 641-649, 2002.

98. Yoneyama M, Kawada K, Gotoh Y, Shiba T, and Ogita K. Endogenous reactive oxygen species are essential for proliferation of neural stem/ progenitor cells. Neurochem Int 56: 740-746, 2010.

99. Yoshida Y, Takahashi K, Okita K, Ichisaka T, and Yamanaka S. Hypoxia enhances the generation of induced pluripotent stem cells. Cell Stem Cell 5: 237-241, 2009.

100. Yuan G, Nanduri J, Khan S, Semenza GL, and Prabhakar NR. Induction of HIF-1alpha expression by intermittent hypoxia: involvement of NADPH oxidase, Ca2 + signaling, prolyl hydroxylases, and mTOR. J Cell Physiol 217: 674-685, 2008.

101. Zhang X, Rielland M, Yalcin S, and Ghaffari S. Regulation and function of FoxO transcription factors in normal and cancer stem cells: what have we learned? Curr Drug Targets 12: 1267-1283, 2011.

102. Zhang $X$, Yalcin S, Lee DF, Yeh TY, Lee SM, Su J, Mungamuri SK, Rimmele P, Kennedy M, Sellers R, Landthaler M, Tuschl T, Chi NW, Lemischka I, Keller G, and Ghaffari S. FOXO1 is an essential regulator of pluripotency in human embryonic stem cells. Nat Cell Biol 13: 1092-1099, 2011.
Address correspondence to:

Dr. Yoon-Young Jang

Stem Cell Biology Laboratory

Department of Oncology

The Sidney Kimmel Comprehensive Cancer Center Johns Hopkins University School of Medicine 1550 Orleans Street, CRB2 Rm552

Baltimore, MD 21231

E-mail: yjang3@jhmi.edu

Date of first submission to ARS Central, September 24, 2012; date of acceptance, October 15, 2012.

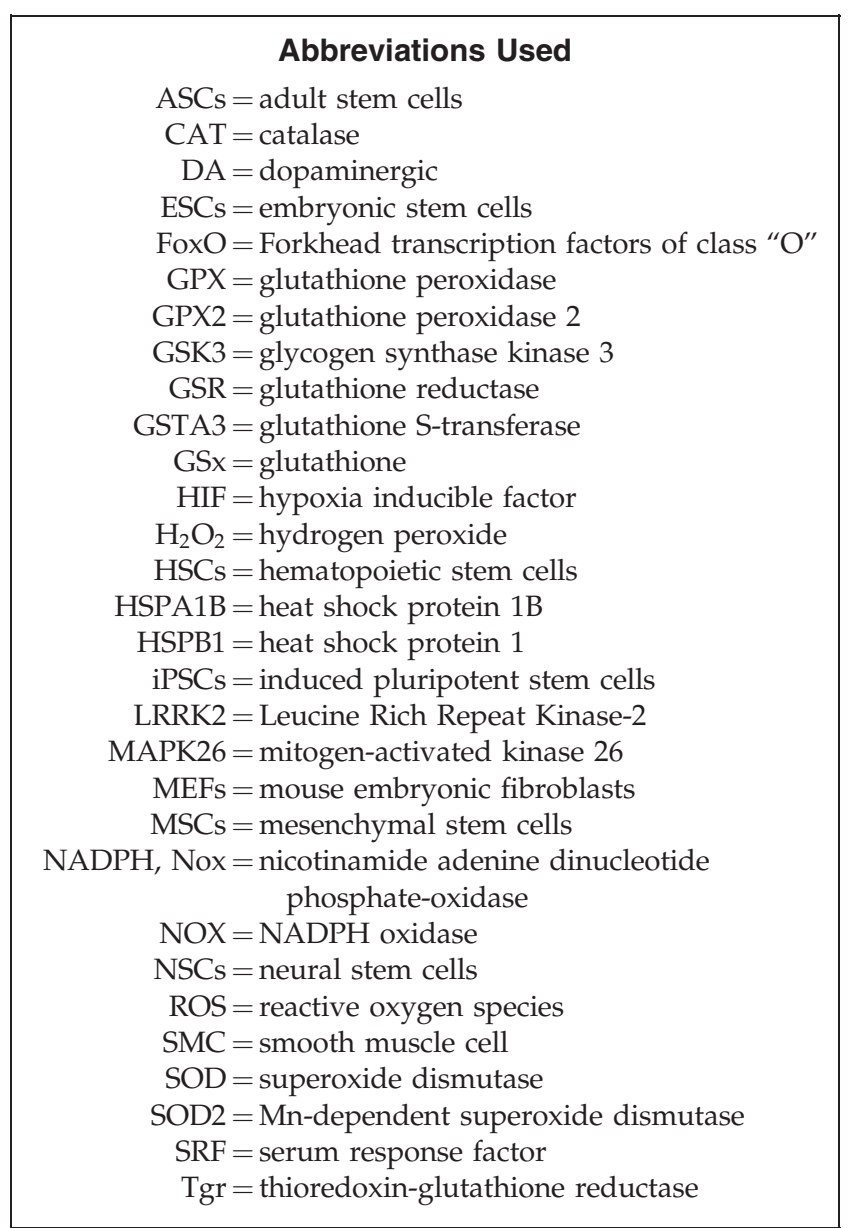

